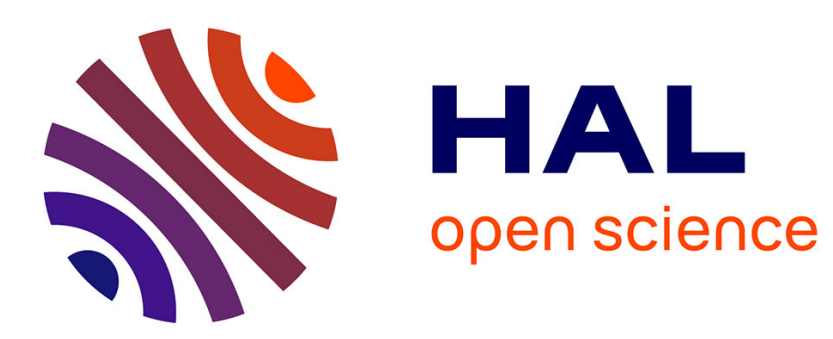

\title{
A di-arginine motif contributes to the ER-localization of the type I transmembrane ER oxidoreductase TMX4
}

Doris Roth, Emily Lynes, Jan Riemer, Henning G. Hansen, Nils Althaus, Thomas Simmen, Lars Ellgaard

\section{- To cite this version:}

Doris Roth, Emily Lynes, Jan Riemer, Henning G. Hansen, Nils Althaus, et al.. A di-arginine motif contributes to the ER-localization of the type I transmembrane ER oxidoreductase TMX4. Biochemical Journal, 2009, 425 (1), pp.195-205. 10.1042/BJ20091064 . hal-00479227

\section{HAL Id: hal-00479227 \\ https://hal.science/hal-00479227}

Submitted on 30 Apr 2010

HAL is a multi-disciplinary open access archive for the deposit and dissemination of scientific research documents, whether they are published or not. The documents may come from teaching and research institutions in France or abroad, or from public or private research centers.
L'archive ouverte pluridisciplinaire HAL, est destinée au dépôt et à la diffusion de documents scientifiques de niveau recherche, publiés ou non, émanant des établissements d'enseignement et de recherche français ou étrangers, des laboratoires publics ou privés. 


\title{
A di-arginine motif contributes to the ER-localization of the type I transmembrane ER oxidoreductase TMX4
}

\author{
Doris Roth ${ }^{*}$, , Emily Lynes ${ }^{\star}$, Jan Riemer ${ }^{*}$, Henning G. Hansen*, Nils Althaus ${ }^{\dagger}$, Thomas \\ Simmen and Lars Ellgaard* \\ *Department of Biology, University of Copenhagen, Denmark; 'Institute of Biochemistry, \\ ETH Zurich, Switzerland; ${ }^{*}$ Department of Cell Biology, University of Alberta, Canada
}

\begin{abstract}
Corresponding author: Lars Ellgaard, Ole Maaløes Vej 5, DK - 2200 Copenhagen N., Denmark. Phone: +45-3532-1725. Fax:+45-3532-2128. E-mail: lellgaard@bio.ku.dk
\end{abstract}

Running title: An RXR signal retains TMX4 in the ER

Key words: oxidoreductase, thioredoxin, PDI, trafficking, endoplasmic reticulum 


\section{SYNOPSIS}

The thiol-disulfide oxidoreductases of the protein disulfide isomerase (PDI) family assist disulfide-bond formation in the endoplasmic reticulum (ER). Here, we show that the previously uncharacterized PDI-family member TMX4 is an N-glycosylated type I membrane protein that localizes to the ER. We also demonstrate that TMX4 contains a single ERlumenal thioredoxin-like domain, which - in contrast to similar domains in other PDIs - is mainly oxidized in living cells. The TMX4 transcript displays a wide tissue distribution, and is strongly expressed in melanoma cells. Unlike many type I membrane proteins, TMX4 lacks a typical C-terminal di-lysine retrieval signal. Instead, the cytoplasmic tail harbors a conserved di-arginine motif of the RXR type. We show that mutation of the RQR sequence in TMX4 to KQK interferes with ER localization of the protein. Moreover, whereas the cytoplasmic region of TMX4 confers ER localization to a reporter protein, the KQK mutant of the same protein redistributes to the cell surface. Overall, features not commonly found in other PDIs characterize TMX4 and suggest unique functional properties of the protein.

\begin{tabular}{|c|c|}
\hline \multicolumn{2}{|c|}{ Abbreviations used } \\
\hline CNX & calnexin \\
\hline DTT & dithio-1,4-threitol \\
\hline Endo $\mathrm{H}$ & endoglycosidase $\mathrm{H}$ \\
\hline ER & endoplasmic reticulum \\
\hline Erol & ER oxidase 1 \\
\hline EST & expressed sequence \\
\hline FCS & fetal calf serum \\
\hline GSH & reduced glutathione \\
\hline GSSG & oxidized glutathione \\
\hline MEM & minimum essential mediun \\
\hline PDI & protein disulfide isomerase \\
\hline redox & reduction-oxidation \\
\hline TMX & thioredoxin-like transmem \\
\hline
\end{tabular}




\section{INTRODUCTION}

The relatively oxidizing conditions inside the lumen of the endoplasmic reticulum (ER) provide an appropriate and supportive environment for oxidative protein folding [1]. In the $\mathrm{ER}$, the correct formation of disulfide bonds is most often a prerequisite for the production of native proteins. During folding, pairs of cysteine thiols are oxidized to form disulfide bonds. Since this process frequently leads to non-native combinations of cysteines, disulfide-bond reduction and isomerization (reshuffling) are critical reactions and often necessary steps en route to the correct structure [2].

Although disulfides form in vitro when oxygen is present, it is an inefficient process in the absence of a catalyst. In the ER, oxidoreductases of the protein disulfide isomerase (PDI) family catalyze oxidation, isomerization and reduction by thiol-disulfide exchange. The PDI-like proteins contain at least one domain similar to thioredoxin, a cytosolic oxidoreductase of $\sim 12 \mathrm{kDa}$. Typically, the active-site residues constitute a CXXC sequence motif (where $\mathrm{X}$ denotes any amino acid residue). The nature of the two variable residues is known to influence the redox potential, i.e. the propensity of the active-site cysteines to be reduced or oxidized, and thereby the redox activity of a given enzyme [3].

The human PDI family counts close to 20 members that differ in size, number and arrangement of thioredoxin-like domains, and in part in tissue distribution [4]. The biological function remains unclear for many. Apart from possible differences in their redox activity, these enzymes probably act on different substrates. For instance, ERp57 likely binds primarily certain cysteine-containing glycoproteins [5]. The function of the PDI-family members is not restricted to oxidative folding. For example, ERp44 regulates $\mathrm{Ca}^{2+}$ release by the inositol 1,4,5-trisphosphate receptor $1, \mathrm{a} \mathrm{Ca}^{2+}$ channel of the ER membrane, through a direct interaction that likely depends on the redox state of the receptor [6]. It is also clear that some of the PDIs perform redox-unrelated functions since they lack both cysteines of the active site. An example is the murine ERp29 that is important for transport across the ER membrane to the cytosol of murine polyoma virus during infection [7]. Here, in a step potentially required for membrane penetration, ERp29 promotes partial unfolding of the major structural viral protein VP1.

While most of the PDI-family members are soluble ER-lumenal proteins, some span the ER membrane. This latter subset of the family is designated as the thioredoxin-like transmembrane - or "TMX" - proteins, and includes TMX, TMX2, and TMX3. All contain a single thioredoxin-like domain, but are otherwise not closely related. TMX has been shown to suppress apoptosis induced by brefeldin A when over-expressed in HEK293 cells [8]. Recently, the interaction between TMX and misfolded MHC class I heavy chain was demonstrated to protect the latter protein from proteasomal degradation, indicating a function of TMX in ER quality control [9] Whereas the knowledge about TMX2 is restricted to its cDNA sequence and tissue distribution [10], TMX3 is well studied in vitro in terms of structure-function relations [11, 12].

Here we characterize TMX4, a novel transmembrane member of the PDI family. We identify TMX4 as a paralog of TMX, and establish that it is an N-glycosylated type I transmembrane protein. We also show that in place of a classical ER-retrieval motif, an RQR sequence in the cytosolic region of TMX4 confers ER localization to the protein. The results suggest that regulated sorting based on sequence features in the C-terminal tail of the protein could modulate the function of TMX4. 


\section{EXPERIMENTAL}

\section{Phylogenetic analysis}

Amino acid sequences of TMX and TMX4 from various organisms were obtained from the Ensembl genome browser. Full-length sequences were aligned on the ch.EMBNET.org server, using ClustalW XXL. The alignments were carried out using the blosum series matrix with an open gap penalty of 10 and an extending gap penalty of 0.05 . Phylogenetic trees were constructed using PhyML [13] and Phylip [14]. Human ERp57 was selected as outgroup.

\section{Cell culture}

The human melanoma cell lines A375M, A375P, LT5-1, and DX3 were kindly provided by Dr. Elena Sviderskaya, Cancer Research UK London Institute, London, UK. All cells were maintained at $37{ }^{\circ} \mathrm{C}$ in alpha-Minimum Essential Medium (MEM; Invitrogen) supplemented with $10 \%$ fetal calf serum (FCS) under $5 \% \mathrm{CO}_{2}$.

\section{Tissue Northern Blot}

A human multiple tissue Northern blot (Ambion) was hybridized with radioactive probes generated from a NotI-XhoI fragment obtained by restriction digestion of pcDNA3.1/TMX4myc. The gel-purified fragment was labeled with $\left[\alpha-{ }^{32} \mathrm{P}\right]-\mathrm{dCTP}$ using the Strip-EZ DNA Kit (Ambion), followed by purification using a Micro Bio-Spin 30 column (Bio-Rad Laboratories) to remove unincorporated nucleotides. Hybridization was done at $65^{\circ} \mathrm{C}$ in ULTRAhyb buffer (Ambion) following the manufacturer's protocol. The probed blot was visualized by autoradiography. The blot was then stripped according to the Strip-EZ DNA Kit protocol and hybridized with probes derived from the $\beta$-actin mouse DNA template delivered with the kit.

\section{RT-PCR analysis}

Total RNA was isolated using the GenElute Total RNA kit (Sigma). The concentration of total RNA was adjusted and mRNA reverse transcribed (Enhanced avian reverse transcriptase kit, Sigma). A PCR was performed with the TMX4-cyt forward and reverse primers that span two TMX4 exons yielding a product of $412 \mathrm{bp}$. As a control, a PCR was performed with the primers Actin for and Actin rev (Table S1). The products were analyzed on 1\% agarose gels.

\section{Gel Electrophoresis and Western Blotting}

Samples were separated on $10 \% 10 \times 10.5 \mathrm{~cm}$ Hoefer minigels (GE Healthcare), with the exception of the CD4-TMX4 chimeras where $7.5 \%$ polyacrylamide was used. Western blotting was performed as described previously [11] using the ECL Advance system for detection (GE Healthcare). Band intensities obtained by autoradiography or Western blotting were quantified using ImageJ [15].

\section{Transfection and Antibodies}

Vero cells used in Figure 4B were transfected using an AMAXA electroporator following the manufacturer's recommendations for each cell lines. For all other experiments, plasmids were transfected into HeLa cells with Lipofectamine 2000 (Invitrogen).

A rabbit polyclonal antiserum (R504) recognizing the cytosolic domain of TMX4 was raised against the peptide sequence DGVTREEVEPEEAEE comprising residues 305-319 (Open Biosystems Inc., Huntsville, AL). The quality of the antiserum was verified on A375P cellular lysates treated with siRNAs directed against TMX4 (see Supplementary Material). The TMX3 antibody has been described before [11]. The mouse monoclonals HA.11 (clone 16B12) against the HA epitope and clone 9E10 against the c-myc epitope were from Covance Research Products. A. Helenius, ETH Zurich, generously provided the polyclonal rabbit antiserum against calnexin. We thank M. Pasdar for the polyclonal anti-E-cadherin antibody. Additional antibodies were purchased as follows: calnexin (Assay Designs), 14-3-3 $\zeta$ (Santa Cruz), mitochondrial complex II (Mitosciences), TMX (Sigma), Alexa Fluor 594 goat anti- 
mouse and Alexa Fluor 488 goat anti-rabbit (Molecular Probes) and horseradish peroxidasecoupled goat anti-mouse and rabbit IgG antibodies were from Pierce.

\section{Mammalian Expression Plasmids}

Detailed information on the various constructs generated in this study is provided in the Supplementary Material.

\section{Immunofluorescence Microscopy}

The experimental conditions for fluorescence microscopy are given in the Supplementary Material.

\section{Endoglycosidase H Digestion}

Endoglycosidase H (Endo H; New England Biolabs) digestions were performed on A375P cell extracts after lysis in loading buffer $(180 \mathrm{mM}$ Tris- $\mathrm{HCl}, \mathrm{pH} 6.8,0.5 \%$ SDS, and $1 \% 2$ mercaptoethanol; Figure 4), or after lysis in lysis buffer $(80 \mathrm{mM}$ Tris- $\mathrm{HCl}, \mathrm{pH} 6.8,1 \%$ SDS; Figure 5). Samples were denatured at $96^{\circ} \mathrm{C}$ for $15 \mathrm{~min}$ and then supplemented with $1 / 10$ volume of $50 \mathrm{mM}$ sodium citrate, $\mathrm{pH} 5.5$, and treated with Endo $\mathrm{H}$ for $1 \mathrm{~h}$ at $37^{\circ} \mathrm{C}$.

\section{Gradients}

ER and Golgi membranes were fractionated on a continuous OPTIPREP gradient (AxisShield plc, Dundee, Scotland) using 25, 20, 15, 10, and 5\% OPTIPREP. A375P cells or HeLa cells transfected with HA-tagged TMX4 were lysed in homogenization buffer $(0.25 \mathrm{M}$ sucrose, $10 \mathrm{mM}$ HEPES-NaOH, pH 7.4, $1 \mathrm{mM}$ EDTA) and passed 15 times through a ballbearing homogenizer (Isobiotec, Heidelberg, Germany) with $18 \mu \mathrm{m}$ clearance. Cell debris and nuclei were pelleted by centrifugation at $1,000 \mathrm{~g}$ for $10 \mathrm{~min}$. The post-nuclear supernatant was overlayed onto the continuous gradient and centrifuged at $32,700 \mathrm{rpm}$ for $3 \mathrm{~h}$ at $4^{\circ} \mathrm{C}$. Six equal fractions were collected from the top of the gradient and precipitated with acetone. Fractions were probed on a Western blot for endogenous TMX4 and HA-TMX4, calnexin (marker for $\mathrm{rER} /$ mitochondria-associated membrane (MAM)), E-cadherin (plasma membrane), 14-3-3६ (Golgi), and complex II (mitochondria).

\section{AMS modification}

A375P cells were soaked in buffer containing N-ethylmaleimide (NEM) before lysis to block free cysteines as described previously [16]. Subsequently, the cell extract was reduced with $10 \mathrm{mM}$ tris(2-carboxyethyl)phosphine hydrochloride (TCEP) for $15 \mathrm{~min}$ and treated with 15 $\mathrm{mM}$ 4-acetamido-4-maleimidylstilbene-2,2-disulfonic acid (AMS) for $1 \mathrm{~h}$ at room temperature. After separation by SDS-PAGE, TMX4, TMX and TMX3 were visualized by Western blotting.

\section{Membrane Association and Proteinase K Protection Assay}

To study the membrane association of TMX4, HA-TMX4-transfected HeLa cells at $60 \%$ confluency were harvested, fractionated and extracted in sodium carbonate as previously described [11]. To determine the topology of TMX4, HeLa cells were transfected with constructs to express HA-TMX4, TMX4-myc or ERp57-HA. $12 \mathrm{~h}$ after transfection, the cells were pulsed overnight at $37{ }^{\circ} \mathrm{C}$ with $125 \mu \mathrm{Ci}\left[{ }^{35} \mathrm{~S}\right]$-methionine/cysteine (PerkinElmer) in 0.5 $\mathrm{ml}$ starvation medium (Dulbecco's modified Eagle's medium without methionine and cystine from Sigma) with $1 \%$ FCS per 35-mm dish. After the pulse, dishes were transferred to ice where all further steps were performed. The cells were washed twice with PBS, scraped off with a rubber policeman in homogenization buffer $(20 \mathrm{mM}$ Hepes- $\mathrm{NaOH} \mathrm{pH} 7.5,0.25 \mathrm{M}$ sucrose, $1 \mathrm{mM}$ dithiothreitol (DTT)) and passed 10 times through a 27 gauge needle. After removal of cell debris by centrifugation at $300 \mathrm{~g}$ for $3 \mathrm{~min}$ at $4{ }^{\circ} \mathrm{C}$, the supernatant was centrifuged at $25,000 \mathrm{~g}$ for $1 \mathrm{~h}$ at $4{ }^{\circ} \mathrm{C}$. The pellet was resuspended in assay buffer $(25 \mathrm{mM}$ Tris- $\mathrm{HCl}, \mathrm{pH} 8,500 \mathrm{mM} \mathrm{NaCl}, 1 \mathrm{mM}$ DTT) and treated with $60 \mu \mathrm{g} / \mathrm{ml}$ proteinase K (PK; Roche Molecular Biochemicals) on ice for $1 \mathrm{~h}$ in the presence or absence of $1 \%$ Triton X-100 (TX-100). After inhibition of proteinase K with $1 \mathrm{mM} \mathrm{PMSF}$, detergent-free samples were 
solubilized with $1 \%$ Triton X-100 before the epitope-tagged proteins were immunoprecipitated, separated by SDS-PAGE and visualized by autoradiography.

\section{Immunoprecipitation}

Lysates were centrifuged at 25,000 g for $30 \mathrm{~min}$, and the supernatants were rotated for $2 \mathrm{~h}$ at $4{ }^{\circ} \mathrm{C}$ with $50 \mu \mathrm{l}$ protein A-sepharose beads (GE Healthcare) preadsorbed with either $2 \mu 1$ HA. 11 or $2 \mu 1$ 9E10. After washing with lysis buffer $(100 \mathrm{mM}$ sodium phosphate, $\mathrm{pH} 8,1 \%$ Triton $\mathrm{X}-100$ ) and $100 \mathrm{mM}$ sodium phosphate $\mathrm{pH}$ 8.0, proteins were eluted from the beads by boiling in sample buffer.

\section{RESULTS}

\section{The TMX4 sequence}

We identified the human gene encoding TMX4 in a GenBank BLAST search using a consensus sequence for a thioredoxin-like domain at the NCBI website (www.ncbi.nlm.nih.gov). The open reading frame encodes a protein of 349 residues ( $39 \mathrm{kDa}$, $\mathrm{pI}=4.3$ ) including a signal sequence for entry into the secretory pathway with a predicted cleavage site between residues 23 and 24 (Figure 1). Sequence alignment with thioredoxinlike domains of known three-dimensional structure from PDI, ERp57 and ERp72 initially suggested that the TMX4 thioredoxin-like domain would cover residues 39 to 136. However, comparison to the NMR structure of the closely related TMX protein [17], revealed that the TMX4 thioredoxin-like domain - like that of TMX - probably possesses an additional Cterminal $\alpha$-helix and a short $\beta$-strand compared to a canonical thioredoxin fold $\left(\alpha_{5}\right.$ and $\beta_{6}$ in Figure 1B). The thioredoxin-like domain is followed by a stretch of 41 residues preceeding a predicted transmembrane helix spanning residues 188-210 (see also Figure 6A). The Cterminal region (residues 211-349) is highly negatively charged with 54 acidic residues and contains no classical ER-localization motif of the $\mathrm{K}(\mathrm{X}) \mathrm{KXX}$ type that targets many type I membrane proteins to the ER [18].

\section{Phylogenetic analysis of the TMX 4 and TMX sequences}

Sequence alignments with other members of the human PDI family revealed that TMX4 is most closely related to TMX. Specifically, the thioredoxin-like domains show 53\% sequence identity. In contrast, the C-terminal region after the predicted transmembrane helix is considerably less well conserved, with the most obvious difference being the length (78 residues in TMX versus 139 residues in TMX4). Transcripts for both proteins are present in a variety of mammals, amphibia, fish and birds but not in plants and yeasts, as shown by database analysis (see also below).

To learn more about the evolutionary relationship between the two proteins, we subjected a variety of TMX and TMX4 sequences to phylogenetic analysis by the maximum likelihood method. The evolutionary tree was rooted using ERp57, a close homolog of PDI (Figure 2). The proteins clustered in three main groups. The cluster shown at the bottom first diverged from a common ancestor and comprises organisms with only one TMX/TMX4 protein. One of these proteins is DPY-11 from C. elegans [19]. We reason that a gene duplication then gave rise to the paralogs TMX and TMX4 that cluster in separate groups. Since the branch lengths represent the number of sequence changes that occurred prior to the next level of separation, the longer branches in the TMX4 cluster indicate that this protein diverged more from the common ancestor than TMX. The results of our analysis were supported by the TreeFam database [20], where the TMX/TMX4 phylogenetic tree structures into the same three groups as presented in Figure 2.

\section{Tissue distribution of TMX4}

The EST-based expression profile of the NCBI Unigene cluster Hs. 169358 suggests a broad tissue distribution of TMX4. We first confirmed this result by examining the transcript levels in a variety of human tissues by Northern blotting (Figure $3 \mathrm{~A}$ ). To this end, [ $\left.{ }^{32} \mathrm{P}\right]$-labeled 
probes for TMX4 were used to hybridize a commercial tissue Northern blot. By autoradiography, we detected a signal at the predicted size of $6.1 \mathrm{~kb}$ for the TMX4 transcript in all tissues tested, although with varying intensity. We further corroborated the broad tissue distribution using RT-PCR analysis to identify TMX4 transcripts in a series of cultured cell lines (Figure 3B).

Next, we probed different human cell lines for the presence of TMX4 by Western blotting using our own polyclonal antibody (R504) raised against the cytosolic domain of TMX4 (see Figure S1 and Figure 4A for specificity of R504). We detected relatively low levels in common lines such as HeLa and HEK293 (data not shown). Instead, a number of melanoma cells contained higher amounts of the protein (Figure 3C) in good agreement with the RT-PCR analysis showing the transcript to be abundant in A375 and Meljuso cells, and the finding that TMX4 expression is almost 10 -fold upregulated upon the transformation of melanocytes to melanoma cells [21].

\section{TMX4 is an N-glycosylated ER protein}

The TMX4 sequence contains one consensus site for N-glycosylation on Asn46 (Figure 1B). To investigate the glycosylation status of endogenous TMX4, we performed Western blot analysis on lysates of A375P melanoma cells treated with Endo $\mathrm{H}$, a glycosidase that removes high-mannose type sugars. The results showed that TMX4 contained a glycan sensitive to Endo $\mathrm{H}$ treatment (Figure 4A), as did the N-terminally HA-tagged protein HA-TMX4 when overexpressed in HeLa cells (Figure S2). To experimentally verify the predicted ER localization of TMX4, we expressed HA-TMX4 in Vero cells. By immunofluorescence microscopy, HA-TMX4 showed a typical reticular ER stain and was found to colocalize with the ER marker calnexin (CNX) (Figure 4B). Moreover, we confirmed that endogenous TMX4 co-fractionated with CNX on an Optiprep gradient. Here, TMX4 showed a distribution that differed slightly from that of CNX (Figure 4C), most likely because CNX not only localizes to the rough ER but also to mitochondria-associated membranes (MAM) [22].

\section{The TMX4 active site is mainly oxidized in cells}

Knowledge about the cellular redox state of a given PDI is a prerequisite for further detailed analysis of its redox properties. To determine the oxidation state of endogenous TMX4, A375P cells were subjected to an alkylation procedure where free cysteines are modified with NEM and cysteines present in disulfides with AMS [16]. As a result of the size difference between the two reagents, the AMS-modified form has decreased gel mobility. On a Western blot for TMX4, we detected two bands corresponding to the oxidized and reduced forms of he active site (Figure 5, upper panel). For comparison, we also determined the redox states of TMX and TMX3 (Figure 5, middle and lower panels). The results showed that whereas TMX4 is primarily oxidized - as also seen for HA-TMX4 expressed in HeLa cells (Figure S3) - TMX is primarily reduced in accordance with recent findings in other cell lines [9]. As we have previously seen for TMX3 in a variety of cultured cells, this protein was also primarily reduced in the $\mathrm{A} 375 \mathrm{P}$ cells $[11,16,23]$.

\section{Membrane topology of TMX4}

We next established that TMX4 is a membrane protein as predicted by the TMHMM algorithm [24] (Figure 6A). Isolated crude membranes from HeLa cells expressing HATMX4 were extracted with sodium carbonate at high $\mathrm{pH}$, and soluble and membraneassociated proteins were separated by high-speed centrifugation and probed by Western blotting. HA-TMX4 was detected exclusively in the membrane fraction, just like the type I transmembrane protein CNX (Figure 6B). The soluble marker protein ERp57 partly fractionated in the insoluble fraction as previously observed for another soluble ER protein, calreticulin, and possibly due to the association with membrane proteins $[11,25]$.

In addition to the transmembrane domain (residues 188-210), two other hydrophobic stretches were detected in TMX4 (Figure 6A). The first, at the very N-terminus, corresponded to the signal sequence. The second comprised residues $147-187$, i.e. the region that links the thioredoxin-like domain to the transmembrane region. Since we could not rule out that this 
linker region was also buried in the membrane, thereby creating a topology with both termini of TMX4 in the ER and a short cytosolic loop, we determined the membrane topology of TMX4 using a proteinase K protection assay (Figure 6C).

Crude membrane extracts from $\left[{ }^{35} \mathrm{~S}\right]$-methionine/cysteine-labeled HeLa cells expressing HA-TMX4 were left untreated or treated with proteinase K, followed by immunoprecipitation of the expressed protein. The untreated sample showed a signal at the expected size for HA-TMX4 of $\sim 45 \mathrm{kDa}$. Upon proteinase K treatment, the band shifted to 25 $\mathrm{kDa}$, a size closely matching that of the $21 \mathrm{kDa}$ expected for HA-TMX4 devoid of the Cterminal cytosolic region. When the ER membrane was solubilized by addition of Triton X100 , proteinase $\mathrm{K}$ gained access to the lumen and the signal disappeared. Thus, the HAtagged $\mathrm{N}$-terminus was localized in the ER as expected from the presence of the $\mathrm{N}$-glycan on Asn46. To examine the orientation of the $\mathrm{C}$-terminus, we performed the proteinase $\mathrm{K}$ assay on HeLa cells expressing C-terminally myc-tagged TMX4. Here, the TMX4-myc signal disappeared almost completely even in the absence of detergent, showing that the myc-tagged C-terminus was not protected inside the ER. The soluble lumenal ERp57 protein was used as a control for membrane integrity. Taken together, the results demonstrated that TMX4 is an $\mathrm{N}$-glycosylated type I transmembrane protein of the ER.

\section{A non-classical sequence motif contributes to ER targeting of TMX4}

Although TMX4 resides in the ER, it lacks a classical K(X)KXX-type ER-localization signal. In multiple sequence alignments of TMX4 we noticed an LRQR sequence conserved among species with only very few exceptions and located close to the C-terminus (Figure 1B). In a number of type II and multispanning membrane proteins a $\Phi / \Psi / \mathrm{R}-\mathrm{R}-\mathrm{X}-\mathrm{R}$ sequence, in which $\Phi / \Psi$ and $X$ represent an aromatic/bulky hydrophobic and any residue, respectively, acts as an ER-localization signal. So far, only one type I membrane protein, the ER lectin VIPL, has been shown to harbor an Arg-based ER-localization motif [26].

To test the possible involvement of the RQR sequence in the ER localization of TMX4, we produced two HA-tagged mutants (Figure 7A) - i) a truncation variant lacking the C-terminal 121 residues ( $\Delta$ tail), and ii) a mutant with the two arginines of the RQR sequence substituted by lysines (KQK). We also wanted to assess a possible influence of the lumenal region of TMX4 in localizing the protein to the ER. Since a construct comprising only the lumenal domain of TMX4 was unstable (half-life $\sim 30$ min compared to $>10$ hours for the wildtype protein (data not shown)), a fusion protein containing the ER-lumenal part of TMX4 combined with the transmembrane and cytosolic regions of CD4 was made (CD4-tail; Figure 7A). Here, CD4 was chosen as a fusion partner since it localizes to the plasma membrane and hence does not contain ER retention/retrieval information itself [27].

After transfecting HeLa cells, we analyzed the cellular localization of the wildtype protein and the three mutants by confocal immunofluorescence microscopy. We found that, unlike the wildtype protein, HA-TMX4 lacking the cytosolic tail partially escaped the ER and reached the plasma membrane. The KQK and CD4-tail mutants showed the same staining pattern as the $\Delta$ tail mutant, also being detected on the cell surface. In conclusion, the RQR sequence was necessary for complete retention of TMX4 fusion proteins in the ER, while neither the lumenal region of TMX4 nor the tail lacking RQR had this ability.

Most likely due to the continuous overexpression of protein, the steady-state localization of all TMX4 variants also included the ER. To clear out the newly synthesized TMX4 variants of the ER, we treated HeLa cells with cycloheximide (CHX), a drug that inhibits protein synthesis (data not shown). Unfortunately, this strategy proved unfeasible because export occurred so slowly that the prolonged CHX treatment induced apoptosis [28]. However, protein aggregation was probably not the cause for the partial ER localization since the immunofluorescence pictures showed no visible aggregates. Moreover, we analyzed the oligomeric state of HA-TMX4 by sucrose gradient velocity centrifugation and found no evidence for Triton X-100-insoluble high-molecular weight complexes (Figure S3). We further ruled out that the plasma membrane localization of the TMX4 mutants was a result of overloading a retention/retrieval mechanism, because the expression levels of the various 
constructs used were similar (data not shown). Taken together, we found that the RQR sequence in the C-terminal region contributes to the ER localization of HA-TMX4.

\section{ER localization conferred by the TMX4 cytosolic tail depends on the RQR sequence}

To further characterize the importance of the TMX4 RQR sequence, we created three new fusion proteins (Figure 8A). All were HA-tagged chimeras between the cytosolic tail of TMX4 and the lumenal region of CD4. Two fusion proteins contained the wildtype sequence for the cytosolic tail of TMX4 but differed with respect to the origin of the transmembrane domain (TMX4 or CD4), whereas the last chimera contained the CD4 lumenal and transmembrane domains fused to the KQK mutant of the TMX4 cytosolic tail.

The chimeras and wildtype HA-CD4 were transfected into HeLa cells that were analyzed by confocal immunofluorescence microscopy (Figure 8B). As expected, we found HA-CD4 strongly staining the plasma membrane. In contrast, the two CD4 chimeras fused to a wildtype TMX4 tail sequence did not reach the cell surface. The nature of the transmembrane domain - whether from CD4 or TMX4 - did not influence the localization pattern. However, the chimeric protein of HA-CD4 fused to the cytosolic tail of TMX4 containing the KQK mutation was clearly detected on the plasma membrane and showed a distribution very similar to wildtype HA-CD4. Overall, the results demonstrated that the cytosolic tail of TMX4 is sufficient for ER targeting and that the RQR sequence is required for this ability.

\section{DISCUSSION}

Here, we provide the first characterization of the novel transmembrane PDI-family member, TMX4. Using phylogenetic analysis we show that TMX4 and TMX are paralogs with closely related N-terminal ER-lumenal regions, including a single thioredoxin-like domain, but quite different C-terminal cytosolic tails. Our analysis revealed that an evolutionarily older version of the two proteins is the DPY-11 protein from C. elegans. In the worm, this protein is expressed exclusively in the hypodermis and is required for body and sensory organ morphogenesis [19]. Curiously, DPY-11 does not harbor the RQR motif but a KKTK sequence at the C-terminus, suggesting a different ER-localization mechanism than TMX4 and TMX. Also, human TMX cannot rescue a dpy-11 mutant in C. elegans [19].

Human TMX4 and most of its orthologs contain a CPSC active-site sequence, and all TMX orthologs have a CPAC motif. These are unusual active-site sequences among the PDIs, where the CGHC sequence is the most common with 16 occurrences among 25 domains with a CXXC sequence, whereas only two other domains contain a CPXC sequence [4]. The enzymes with the common CGHC motif generally seem to have moderate reduction potentials that are neither especially oxidizing nor reducing with values around $-160 \mathrm{mV}$, as measured for TMX3, ERp57 and PDI [11, 29-31]. The cellular redox state of these proteins and TMX is partially oxidized $([9,11,16,23]$; Fig. 5), but not nearly to the extent seen in TMX4. Since the active-site sequence motif of TMX is very similar to that of TMX4, it is, however, unlikely that the uncommon CPSC motif in TMX4 can account for the observed redox state. Rather, currently unknown features of the TMX4 sequence that influence the redox properties of the protein, or its cellular redox regulation set it apart from the other PDIfamily members inyestigated to date. While the unusually oxidized redox state of TMX4 could well have interesting functional implications, we do presently not know the exact cellular function of the protein, although it could potentially be involved in ER quality control like TMX [9].

Neither TMX4 nor TMX contain a C-terminal K(X)KXX-type ER-retrieval signal. Using chimeric molecules with CD4 that normally localizes to the plasma membrane, we mapped the TMX4 ER-localization signal to the cytosolic tail. Here, we found that even the conservative substitution of the two arginines in the RQR motif by lysines resulted in partial surface expression of TMX4 (Figure 7). Indeed, the RQR sequence constitutes a bona fide ER-localization signal as further supported by the requirement of the two arginines for ER localization of TMX4 chimeras with CD4. 
It is interesting to consider why TMX4 (and potentially TMX, which also harbors a conserved Arg-based sequence motif; Figure 1B) uses an Arg-based signal and not the classical C-terminal $\mathrm{K}(\mathrm{X}) \mathrm{KXX}$ motif. It is now clear that both types of signals function by COPI-mediated retrieval to the ER although binding of the involved sequence motifs occurs through different COPI subunits [32,33]. Both motifs can prevent forward transport of unassembled subunits until they are sterically hidden by oligomerization in the ER [34, 35]. However, unlike the $\mathrm{K}(\mathrm{X}) \mathrm{KXX}$ sequences that are mainly found in ER-resident proteins, Argbased signals are often present on multimeric proteins destined for the plasma membrane. In addition to masking by multimeric assembly, Arg-based motifs can be overcome by cytosolic interaction partners such as 14-3-3 proteins that promote cell surface expression of ion channels and receptors [36-38]. In the case of TMX4 (and TMX) suppression of the Argbased motif, potentially in response to specific cellular conditions, might therefore allow the relocalization of the protein.

Features in addition to the RQR motifs in TMX4 and TMX suggest that their trafficking could be regulated by multiple factors. The tails of both proteins contain a long stretch of negatively charged residues comprising two experimentally verified phosphorylation sites on serine residues 251 and 259 for TMX4 (Figure 1B), and on serine residues 247 and 253 for TMX [39]. The combination of these sequence features has been shown to constitute a potential binding site for PACS-2, a cytosolic sorting protein that uses COPI to target its substrate proteins to the ER dependent on their phosphorylation state [40, 41]. While speculative at present, it is conceivable that the subcellular localization and thereby the functions of TMX4 and TMX are modulated by binding (potentially phosphorylation-dependent) of regulatory sorting factors that target binding sites in the cytosolic tail.

\section{ACKNOWLEDGEMENTS}

We thank the Institute of Biochemistry, ETH Zurich, for the continued support, all members of the Ellgaard lab for critical reading of the manuscript, Zhila Nikrozi for technical support, and I. Novak for help with immunofluorescence microscopy. Constructs, cells and antibodies were kindly supplied by A. Helenius, R. Sitia, E. Sviderskaya, H. P. Hauri, R. HartmannPetersen, S. T. Christensen, M. Pasdar, and K. Karjalainen. Work in the Simmen lab is funded by NCIC grant \#17291 (Terry Fox Foundation) and AHFMR grant 200500396. Funding to the Ellgaard lab obtained from the ETH Zurich, The Roche Research Foundation and Novo Nordisk Fonden is gratefully acknowledged. The authors declare they have no conflicts of interest. 


\section{REFERENCES}

1 Ellgaard, L. and Helenius, A. (2003) Quality control in the endoplasmic reticulum. Nat. Rev. Mol. Cell Biol. 4, 181-191

2 Jansens, A., van Duijn, E. and Braakman, I. (2002) Coordinated nonvectorial folding in a newly synthesized multidomain protein. Science. 298, 2401-2403

3 Grauschopf, U., Winther, J. R., Korber, P., Zander, T., Dallinger, P. and Bardwell, J. C. (1995) Why is DsbA such an oxidizing disulfide catalyst? Cell. 83, 947-955

4 Appenzeller-Herzog, C. and Ellgaard, L. (2008) The human PDI family: versatility packed into a single fold. Biochim Biophys Acta. 1783, 535-548

5 Jessop, C. E., Chakravarthi, S., Garbi, N., Hammerling, G. J., Lovell, S. and Bulleid, N. J. (2007) ERp57 is essential for efficient folding of glycoproteins sharing common structural domains. EMBO J. 26, 28-40

6 Higo, T., Hattori, M., Nakamura, T., Natsume, T., Michikawa, T. and Mikoshiba, K. (2005) Subtype-specific and ER lumenal environment-dependent regulation of inositol 1,4,5trisphosphate receptor type 1 by ERp44. Cell. 120, 85-98

7 Magnuson, B., Rainey, E. K., Benjamin, T., Baryshev, M., Mkrtchian, S. and Tsai, B. (2005) ERp29 triggers a conformational change in polyomavirus to stimulate membrane binding. Mol. Cell. 20, 289-300

8 Matsuo, Y., Akiyama, N., Nakamura, H., Yodoi, J., Noda, M. and Kizaka-Kondoh, S. (2001) Identification of a novel thioredoxin-related transmembrane protein. J. Biol. Chem. 276, 10032-10038

9 Matsuo, Y., Masutani, H., Son, A., Kizaka-Kondoh, S. and Yodoi, J. (2009) Physical and Functional Interaction of Transmembrane Thioredoxin-related Protein (TMX) with MHC Class I Heavy Chain: Redox-based Protein Quality Control and Its Potential Relevance to Immune Responses. Mol. Biol. Cell, In press

10 Meng, X., Zhang, C., Chen, J., Peng, S., Cao, Y., Ying, K., Xie, Y. and Mao, Y. (2003) Cloning and identification of a novel cDNA coding thioredoxin-related transmembrane protein 2. Biochem. Genet. 41, 99-106

11 Haugstetter, J., Blicher, T. and Ellgaard, L. (2005) Identification and Characterization of a Novel Thioredoxin-related Transmembrane Protein of the Endoplasmic Reticulum. J. Biol. Chem. 280, 8371-8380

12 Haugstetter, J., Maurer, M. A., Blicher, T., Pagac, M., Wider, G. and Ellgaard, L. (2007) Structure-function analysis of the endoplasmic reticulum oxidoreductase TMX3 reveals interdomain stabilization of the N-terminal redox-active domain. J. Biol. Chem. 282, 33859-33867

13 Guindon, S. and Gascuel, O. (2003) A simple, fast, and accurate algorithm to estimate large phylogenies by maximum likelihood. Syst. Biol. 52, 696-704

14 Felsenstein, J. (1989) Cladistics. 5, 164-166

15 Abramoff, M. D., Magelhaes, P. J. and Ram, S. J. (2004) Image Processing with ImageJ. Biophotonics Int 11, 36-42

16 Appenzeller-Herzog, C. and Ellgaard, L. (2008) In vivo reduction-oxidation state of protein disulfide isomerase: the two active sites independently occur in the reduced and oxidized forms. Antiox. Red. Signal. . 10, 55-64

17 Tochio, N., Koshiba, S., Inoue, M., Kigawa, T. and Yokoyama, S. (2005) The solution structure of the thioredoxin-like domain of human thioredoxin-related transmembrane protein., PDB accession number: 1X5E, to be published

18 Teasdale, R. D. and Jackson, M. R. (1996) Signal-mediated sorting of membrane proteins between the endoplasmic reticulum and the golgi apparatus. Annu. Rev. Cell Dev. Biol. 12, 27-54

19 Ko, F. C. and Chow, K. L. (2002) A novel thioredoxin-like protein encoded by the C. elegans dpy-11 gene is required for body and sensory organ morphogenesis. Development. 129, $1185-1194$

20 Li, H., Coghlan, A., Ruan, J., Coin, L. J., Heriche, J. K., Osmotherly, L., Li, R., Liu, T., Zhang, Z., Bolund, L., Wong, G. K., Zheng, W., Dehal, P., Wang, J. and Durbin, R. 
(2006) TreeFam: a curated database of phylogenetic trees of animal gene families. Nucleic Acids Res. 34, D572-D580

21 Hoek, K., Rimm, D. L., Williams, K. R., Zhao, H., Ariyan, S., Lin, A., Kluger, H. M., Berger, A. J., Cheng, E., Trombetta, E. S., Wu, T., Niinobe, M., Yoshikawa, K., Hannigan, G. E. and Halaban, R. (2004) Expression profiling reveals novel pathways in the transformation of melanocytes to melanomas. Cancer Res. 64, 5270-5282

22 Myhill, N., Lynes, E. M., Nanji, J. A., Blagoveshchenskaya, A. D., Fei, H., Carmine Simmen, K., Cooper, T. J., Thomas, G. and Simmen, T. (2008) The subcellular distribution of calnexin is mediated by PACS-2. Mol. Biol. Cell. 19, 2777-2788

23 Appenzeller-Herzog, C., Riemer, J., Christensen, B., Sørensen, E. S. and Ellgaard, L. (2008) A novel disulphide switch mechanism in Erolalpha balances ER oxidation in human cells. EMBO J. 27, 2977-2987

24 Sonnhammer, E. L., von Heijne, G. and Krogh, A. (1998) A hidden Markov model for predicting transmembrane helices in protein sequences. Proc. Int. Conf. Intell. Syst. Mol. Biol. 6, 175-182

25 Pagani, M., Fabbri, M., Benedetti, C., Fassio, A., Pilati, S., Bulleid, N. J., Cabibbo, A. and Sitia, R. (2000) Endoplasmic reticulum oxidoreductin 1-lbeta (ERO1-Lbeta), a human gene induced in the course of the unfolded protein response. J. Biol. Chem. 275, 23685-23692 26 Nufer, O., Mitrovic, S. and Hauri, H. P. (2003) Profile-based data base scanning for animal L-type lectins and characterization of VIPL, a novel VIP36-like endoplasmic reticulum protein. J. Biol. Chem. 278, 15886-15896

27 Maddon, P. J., Littman, D. R., Godfrey, M., Maddon, D. E., Chess, L. and Axel, R. (1985) The isolation and nucleotide sequence of a cDNA encoding the T cell surface protein T4: a new member of the immunoglobulin gene family. Cell. 42, 93-104

28 Natoli, G., Costanzo, A., Guido, F., Moretti, F., Bernardo, A., Lelio Burgio, V., Agresti, C. and Levrero, M. (1998) Nuclear Factor kB-independent Cytoprotective Pathways Originating at Tumor Necrosis Factor Receptor-associated Factor 2. J Biol Chem. 273, 31262-31272

29 Frickel, E. M., Frei, P., Bouvier, M., Stafford, W. F., Helenius, A., Glockshuber, R. and Ellgaard, L. (2004) ERp57 Is a Multifunctional Thiol-Disulfide Oxidoreductase. J. Biol. Chem. 279, 18277-18287

30 Raturi, A. and Mutus, B. (2007) Characterization of redox state and reductase activity of protein disulfide isomerase under different redox environments using a sensitive fluorescent assay. Free Radic. Biol. Med. 43, 62-70

31 Darby, N. J. and Creighton, T. E. (1995) Characterization of the active site cysteine residues of the thioredoxin-like domains of protein disulfide isomerase. Biochemistry. 34, 16770-16780

32 Eugster, A., Frigerio, G., Dale, M. and Duden, R. (2004) The alpha- and beta'-COP WD40 domains mediate cargo-selective interactions with distinct di-lysine motifs. Mol. Biol. Cell. 15, 1011-1023

33 Michelsen, K., Schmid, V., Metz, J., Heusser, K., Liebel, U., Schwede, T., Spang, A. and Schwappach, B. (2007) Novel cargo-binding site in the beta and delta subunits of coatomer. J. Cell Biol. 179, 209-217

34 Letourneur, F., Hennecke, S., Demolliere, C. and Cosson, P. (1995) Steric masking of a dilysine endoplasmic reticulum retention motif during assembly of the human high affinity receptor for immunoglobulin E. J Cell Biol. 129, 971-978

35 Margeta-Mitrovic, M., Jan, Y. N. and Jan, L. Y. (2000) A trafficking checkpoint controls GABA(B) receptor heterodimerization. Neuron. 27, 97-106

36 Nufer, O. and Hauri, H. P. (2003) ER export: call 14-3-3. Curr. Biol. 13, R391-393

37 Michelsen, K., Yuan, H. and Schwappach, B. (2005) Hide and run. Arginine-based endoplasmic-reticulum-sorting motifs in the assembly of heteromultimeric membrane proteins. EMBO Rep. 6, 717-722

38 Mrowiec, T. and Schwappach, B. (2006) 14-3-3 proteins in membrane protein transport. Biol. Chem. 387, 1227-1236 
39 Olsen, J. V., Blagoev, B., Gnad, F., Macek, B., Kumar, C., Mortensen, P. and Mann, M. (2006) Global, in vivo, and site-specific phosphorylation dynamics in signaling networks. Cell. 127, 635-648

40 Kottgen, M., Benzing, T., Simmen, T., Tauber, R., Buchholz, B., Feliciangeli, S., Huber, T. B., Schermer, B., Kramer-Zucker, A., Hopker, K., Simmen, K. C., Tschucke, C. C., Sandford, R., Kim, E., Thomas, G. and Walz, G. (2005) Trafficking of TRPP2 by PACS proteins represents a novel mechanism of ion channel regulation. EMBO J. 24, 705-716

41 Simmen, T., Aslan, J. E., Blagoveshchenskaya, A. D., Thomas, L., Wan, L., Xiang, Y., Feliciangeli, S. F., Hung, C. H., Crump, C. M. and Thomas, G. (2005) PACS-2 controls endoplasmic reticulum-mitochondria communication and Bid-mediated apoptosis. EMBO J. 24, 717-729 


\section{FIGURE LEGENDS}

Figure 1. Sequence features and evolutionary conservation of TMX4.

(A) Graphical overview of TMX4. The following sequence features are indicated: predicted signal peptide (SP), N-glycosylation consensus site (asterisk), thioredoxin-like domain (Trx), active-site motif (CPSC) and predicted transmembrane domain (TM). (B) Multiple sequence alignment of TMX4 from Homo sapiens (Ensembl Gene ID ENSG00000125827), Erinaceus europaeus (Ensembl Gene ID ENSEEUG00000014678), Canis familiaris (Ensembl Gene ID ENSCAFG00000005883), Ornithorhynchus anatinus (Ensembl Gene ID ENSOANG00000008415) and human TMX (Ensembl Gene ID ENSG00000139921). Black boxes represent amino acid identities and gray boxes show amino acid similarities. The following features are indicated above the sequence: Signal sequence (striped rectangle), Nglycosylation consensus site (asterisk), CPXC active-site sequence (double-headed arrow), transmembrane region (checkered rectangle), phosphorylation sites (hashes), and RQR motif (diamonds). Below the sequence, rectangles and arrows indicate $\alpha$-helices and $\beta$-strands, respectively, corresponding to the positions of secondary structure elements in the NMR structure of the thioredoxin-like domain of TMX.

\section{Figure 2. Phylogenetic tree for TMX and TMX4.}

The tree was rooted by including human ERp57 as outgroup. Clustered groups of the TMX, TMX4 (grey) and TMX/TMX4 proteins are indicated. Separate branches are labeled with the name of the individual organisms.

Figure 3. Tissue distribution of TMX4.

(A) The TMX4 mRNA is expressed in a wide array of tissues. A human tissue Northern blot (NB) was radioactively probed for the presence of TMX4 transcripts (EnsEMBL transcript ID ENST00000246024; predicted size: $6.1 \mathrm{~kb}$ ) and analyzed by autoradiography. A background band $(*)$ in all tissues migrated at the height of $28 \mathrm{~S}$ ribosomal RNA $(4.8 \mathrm{~kb})$. As a control, the blot was stripped and labeled against the $\beta$-actin transcript (2.0 kb with an additional $1.8 \mathrm{~kb}$ isoform in muscle tissues). (B) Semi-quantitative PCR on various cultured cell lines. A375: human melanoma; HEK293: human embryonic kidney; HeLa: cervical epithelial carcinoma; HepG2: hepatocellular carcinoma, CFPAC-1: pancreatic adeno carcinoma; Meljuso: melanoma; HT1080: fibrosarcoma breast cancer; OVCAR3, SKOV3: ovarian epithelial carcinoma; LRB003: embryonic stem cells. Total RNA was isolated, its concentration adjusted and mRNA reverse transcribed. A PCR was performed with forward and reverse primers specific for a region that spans two TMX4 exons (expected product size: $412 \mathrm{bp}$ ). A PCR with primers specific for actin was performed as a control. (C) Western blot analysis of extracts of the human melanoma cell lines M2, A375M, A375P, LT5-1 and DX3 with the polyclonal R504 antibody against TMX4. In the lower panel the actin signal is shown as a loading control.

Figure 4. TMX4 is an N-glycosylated protein of the ER.

(A) Western blot analysis of TMX4 in A375P melanoma cells. Lysates were treated with Endo $\mathrm{H}$ as indicated. The asterisk denotes a background band. (B) HA-TMX4 colocalizes with the ER marker calnexin (CNX) by confocal immunofluorescence microscopy. Vero cells were transfected with pcDNA3.1/HA-TMX4, fixed and analyzed by immunofluorescence microscopy using antibodies against the HA epitope and CNX. (C) OPTIPREP fractionation of TMX4 and organelle marker proteins. A375P (for endogenous TMX4) and HeLa cells transfected with HA-tagged TMX4 were lysed and cellular membranes were fractionated on a discontinuous OPTIPREP gradient. Fractions 1-6 were blotted with antibodies against the indicated marker proteins (calnexin ( $\mathrm{rER} /$ mitochondria-associated membrane (MAM)), Ecadherin (cell surface), 14-3-3̧ (Golgi) and mitochondrial complex II (mitochondria)).

Figure 5. Endogenous TMX4 is predominantly oxidized in cells. 
Following in situ blocking of free cysteines by NEM, A375P cell lysates were reduced by TCEP and treated with AMS, then separated by SDS-PAGE and finally analysed by Western blotting (WB). Cells were pretreated with $10 \mathrm{mM}$ DTT and $5 \mathrm{mM}$ diamide to obtain controls for the fully reduced (RED) and oxidized (OX) forms, respectively, of TMX4 (upper panel), TMX (middle panel) and TMX3 (lower panel).

Figure 6. TMX4 is a type $I$ transmembrane protein.

(A) Transmembrane (TM) topology prediction for TMX4. The TMX4 amino acid sequence was analyzed using the TMHMM algorithm, and the probability for individual residues to be in a transmembrane helix was plotted versus the residue number. Residues 5-35 constitute the predicted signal sequence. (B) HA-TMX4 is an integral membrane protein. After subjecting crude membranes of HeLa cells expressing HA-TMX4 to alkali extraction, the soluble and insoluble fractions were separated by ultracentrifugation through a sucrose cushion. The distributions of HA-TMX4 and the control proteins CNX (a type I transmembrane protein) and ERp57 (a soluble ER protein) were visualized by Western blotting. (C) Experimental verification of the TMX4 topology. HeLa cells expressing HA-TMX4, TMX4-myc and HAERp57, respectively, were labeled with $\left.{ }^{35} \mathrm{~S}\right]$-methionine/cysteine. Crude membranes were isolated and mock treated or treated with Proteinase $\mathrm{K}(\mathrm{PK})$ in the presence or absence of $1 \%$ TX-100. Finally, samples were immunoprecipitated (IP) as indicated, separated by SDSPAGE and visualized by autoradiography.

Figure 7. The cytoplasmic RQR motif contributes to ER localization of TMX4.

(A) Schematic representation of HA-TMX4 variants used for localization studies: full-length wildtype HA-TMX4 (WT); HA-TMX4 lacking the cytoplasmic region ( $\Delta$ tail); HA-TMX4 with the two arginines of the RQR sequence substituted by lysines (KQK); HA-TMX4, where the cytoplasmic region was replaced by the cytoplasmic tail of CD4 (CD4-tail). SP, TMX4 signal peptide; TM, transmembrane region. (B) Mutants lacking the RQR motif partially escape the ER and reach the plasma membrane, visualized by myristoylated and palmitoylated Yellow Fluorescent Protein (MyrPaim-YFP; right). Vero cells were transfected with the four TMX4 constructs and stained with HA.11 after fixation and permeabilization (left). For detection of protein on the cell surface, cells were incubated with HA.11 before fixation (middle). The cells displayed are representative for the transfected cells. IF: immunofluorescence.

Figure 8. The TMX4 RQR sequence prevents cell surface expression of CD4.

(A) Schematic overview of HA-tagged CD4 and CD4/TMX4 chimeras. All possess the ERlumenal region of $\mathrm{CD} 4\left(\mathrm{~L}_{\mathrm{CD} 4}\right)$ but differ in the transmembrane domain $(\mathrm{TM})$ and cytosolic tail (C), which are from CD4, TMX4 or TMX4-KQK as indicated. SP, CD4 signal peptide. (B) CD4 fusion proteins carrying the cytosolic region of WT-TMX4 do not reach the cell surface marked by MyrPalm-YFP, whereas the cytosolic tail of TMX4-KQK allows the escape to the plasma membrane. HeLa cells were transfected with the indicated HA-CD4/TMX4 constructs, fixed and permeabilized or not before staining with HA.11 to detect intracellular and cell surface expression, respectively. The cells displayed are representative for the transfected cells. 
A

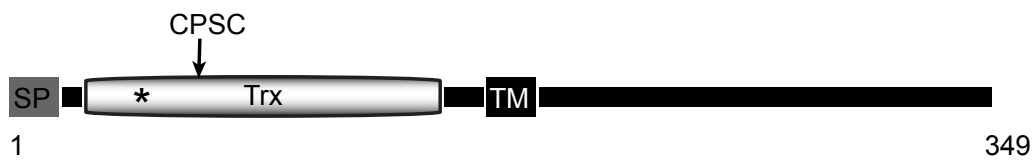

B

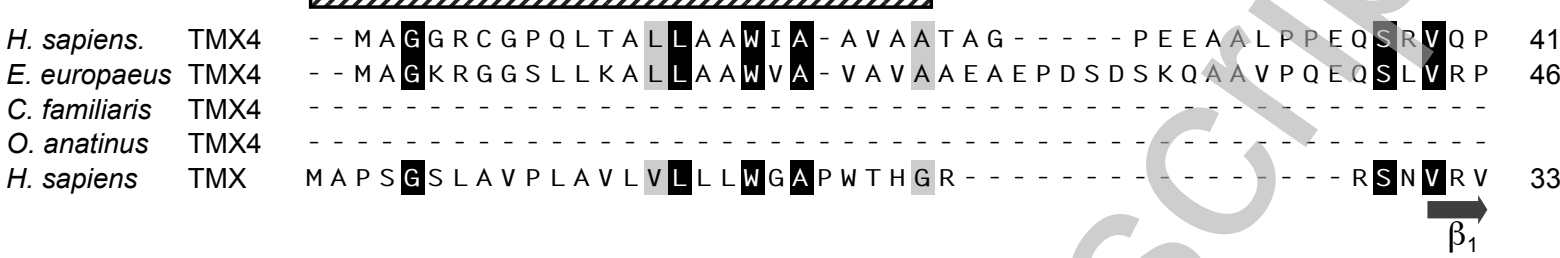

* $\stackrel{\mathrm{CPXC}}{\longleftrightarrow}$

H. s. TMX4 42 MTA SN WT L VMEGEWMLKFYAPWCPSCQQTDSEWEAFARNGEILQI SVGKVDV 93

E. e. TMX4 47 MTASNWTLVMEGEWMLKFYAPWCPSCQQTDSEWEMFAKNGDLLQISVGKVDV 98

C. f. TMX4 -.....- DWLFFFY SYAPWCPSCQQTDSEWETFAKNGEVLHISVGKVDV 42

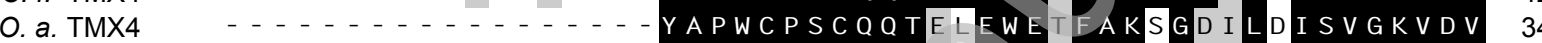

H. S. TMX 34 I TDENWRELLEGDWMI EFYAPWCPAC Q N L Q PEWESFAEWGEDLEVNIAKVDV 85

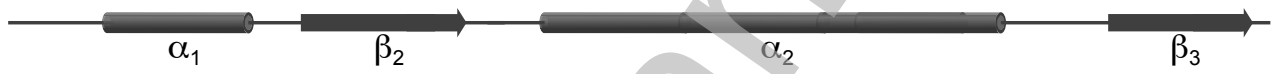

H. s. TMX4 94 I QEPGLSGRFFVTTLPAFFHAKDGIFRRYRGPGIFEDLQNYILEKKWQSVEP 145

E. e. TMX4 99 I QEPGLSGRFFVTTLPAFFXAKDG-TFRYRG-GIYEDLQNYILEKKWQSVEP 148

C. f. TMX4 43 I QEPGLSGRFFVTTLPAFFHAKDGIFRRYRGPGVYEDLQNYILEKKWQSVEP 94

O. a. TMX4 35 TQEPGLSGRFFVTTLPTIFHAKDGIFRRYRGPGISKDLQNYILEKKWEAVEP 86

H. s. TMX 86 TEQPGLSGRFI I TALPTIYHCKDGEFRRYQGPRTKKDFINFISDKEWKS IEP 137

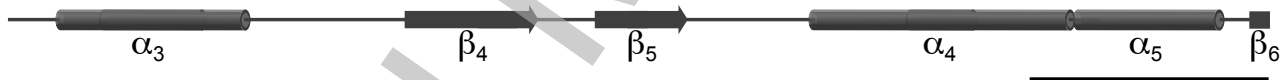

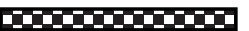

H. s. TMX4 146 LTGWKSPASLTMSGMAGLFS ISGK I WHLHNYFTVTLG I PAWCSYVFFV IATL 197

E. e. TMX4 149 LTGWKSPASLTMSGMAGLFS ISGOI WHLHNYFTVTLGVPAWCSYVFFI IATL 200

C.f. TMX4 95 LTGWKSPASLTMSGMAGLFS I S GKI WHLHNYFTVTLGIPAWCSYIFFVMATL 146

O. a. TMX4 87 VAGWKSPSS I TMSGMA GLF SLS GWI RQLHSYFTGPLG I PVWGS Y VIF I VATL 138

H. s. TMX 138 VS SWFGPGS VLMSSMSALFQLSMWIRTCHNYFIEDLGLPVWGSYTVFALATL 189

$\Rightarrow$

\section{Hom}

H. s. TMX4 198 VFGLFMGLVLVVISECFYVPLPRHLSERSEQNRRSEEAHRAEQLQDAEEEKD 249 E. e. TMX4 201 IFGLFMGLVLVLISECFYVPFPRHLSERSD-TRRSRRPHSPKELQDAEGEKA 251 C.f. TMX4 147 I FGLFMGLVLVVISECFYI PLPRRLSEHADWNEGGECLFI IEFQGEKKEEKI 198 O. a. TMX4 139 V I GLLLGLI V VLLSDCFCPPKPRAERSVARSCLGNDEDSGEQARNKKKTLVK 190 H. s. TMX 190 F SGLLLGLCMIF V A D C LCP SKRRRP Q P . . . . . . . . . . . . . . .

$$
\text { \# \# }
$$

H. s. TMX4 250 D SNEEE-NKDSLVDDEEEKEDLGDEDEAEEEEEEDNLAAGVDEERSEANDQG 300 E. e. TMX4 252 DSNEDE-NKDSLI DEEEEKEDPGDEDEGEDEEEEDNLTAGMDEERSDSQDHR 302 C.f. TMX4 199 LTH I PER SKDVLIS S I A QEQT QRPEDAHKAEQLQDS SAPPVGEGRNDTQGQG 250 O. a. TMX4 191 SRVKEKP PKHLYVVTEKENEALI VEDLGEISEEKKNLFSDREEERSHSNEES 242 H. S. TMX $217 \ldots \ldots$......... Y PYPSKKLLSESA QPLKKVEEEQEADEEDVSEEEAESKE- - 255

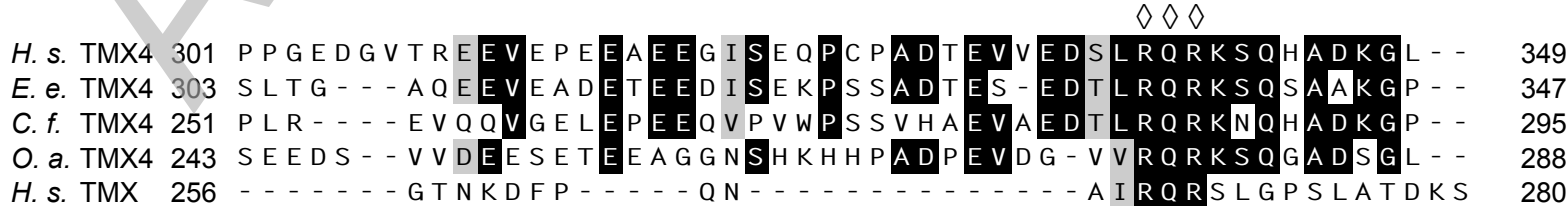




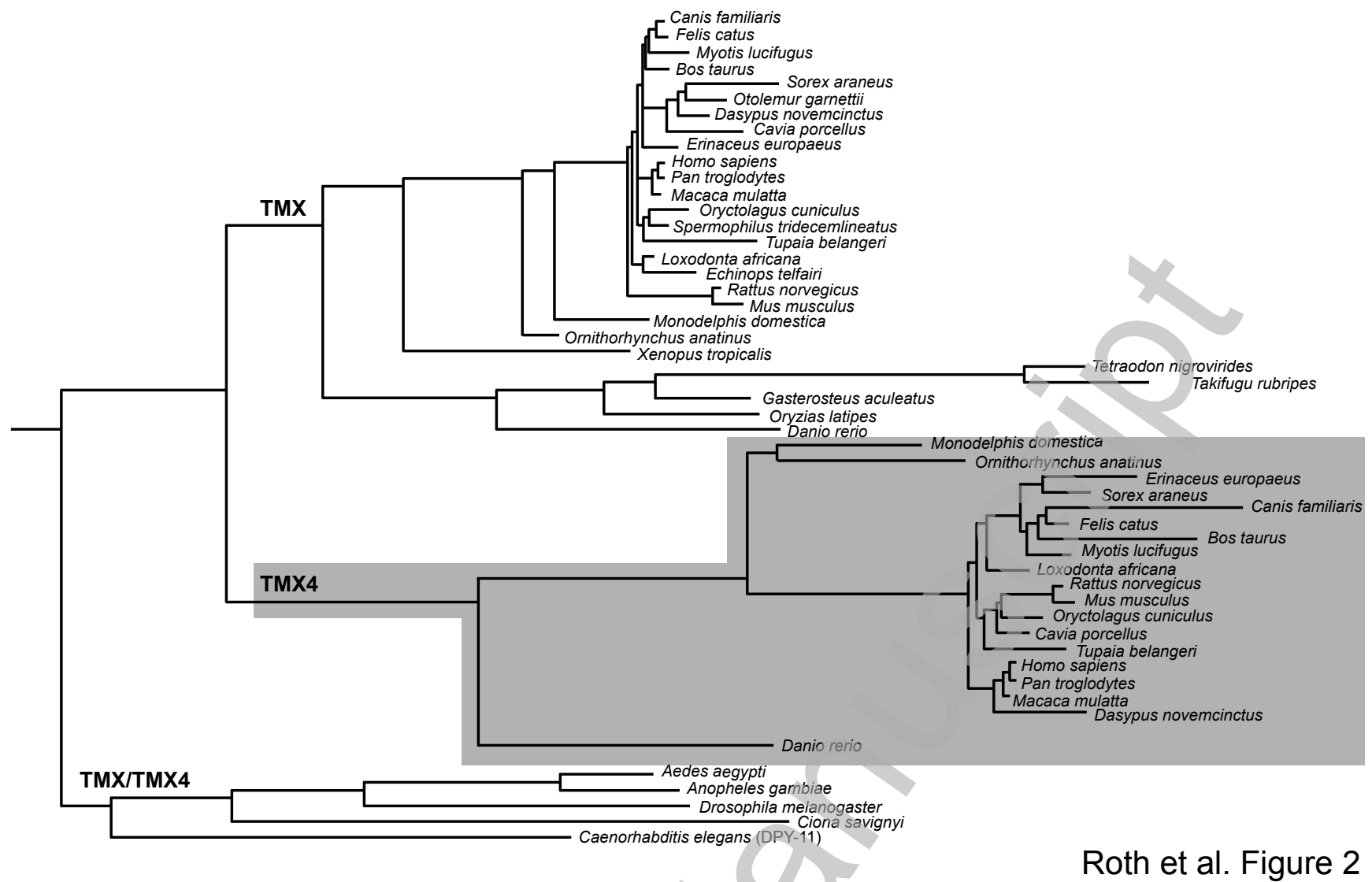

Licenced copy. Copying is not permitted, except with prior permission and as allowed by law. (C) 2009 The Authors Journal compilation (c) 2009 Portland Press Limited 
A

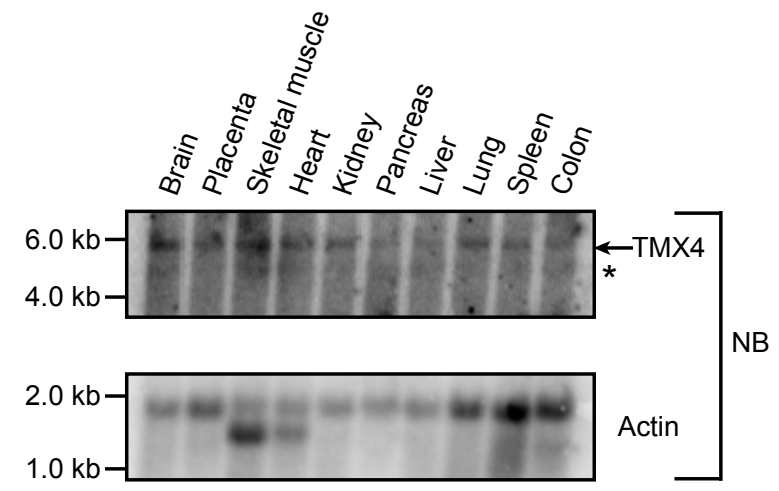

B

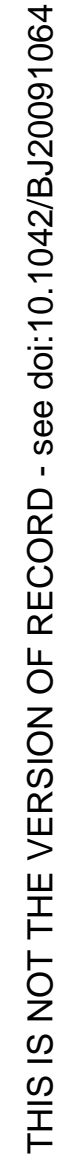

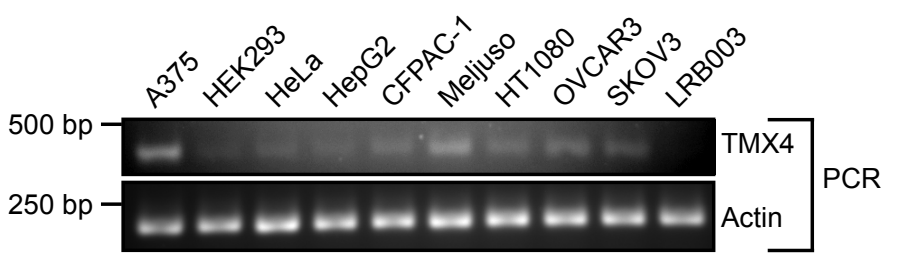

C

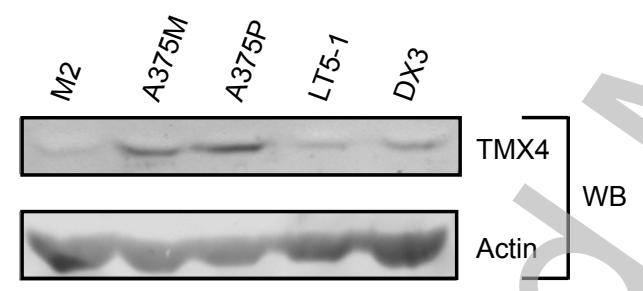

Roth et al. Figure 3 
A

B

HA-TMX4
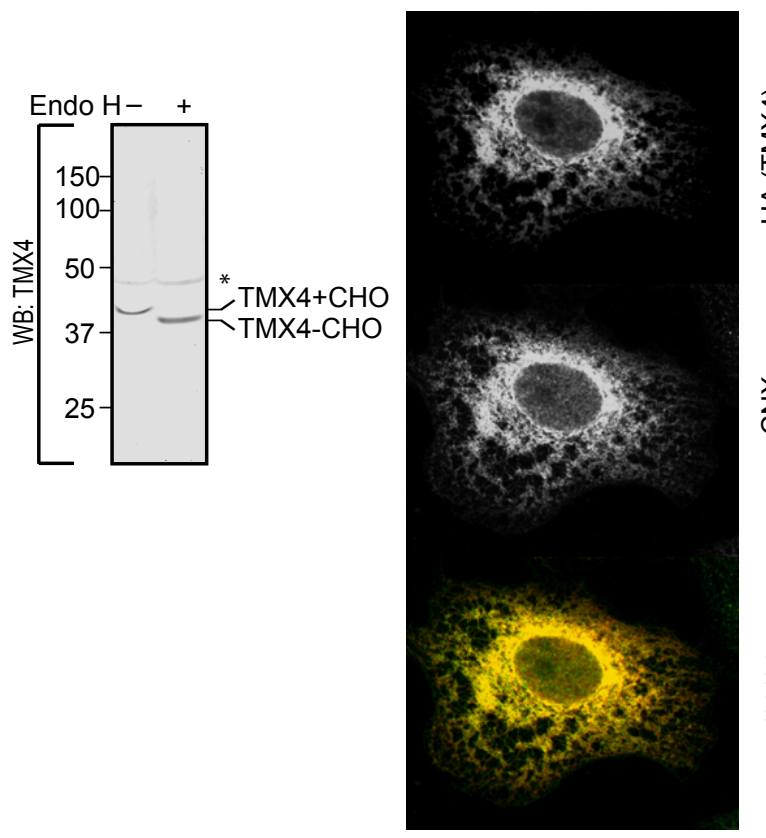

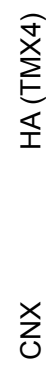

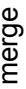

C

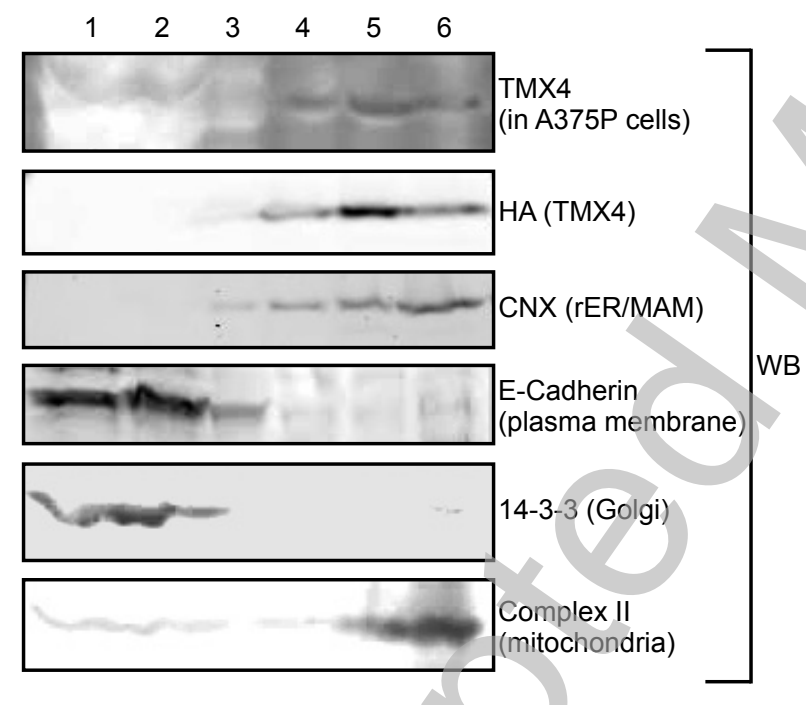

Roth et al. Figure 4

Licenced copy. Copying is not permitted, except with prior permission and as allowed by law. (C) 2009 The Authors Journal compilation (c) 2009 Portland Press Limited 


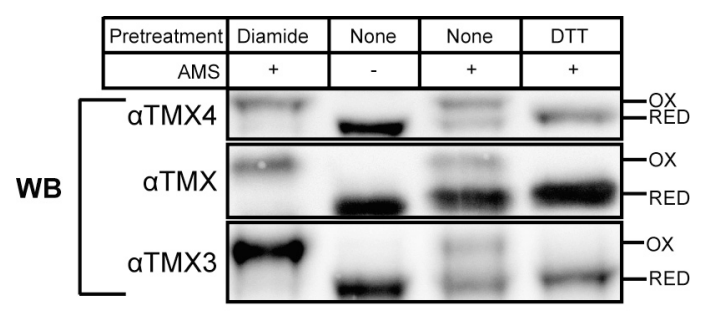

Roth et al. Figure 5 
A

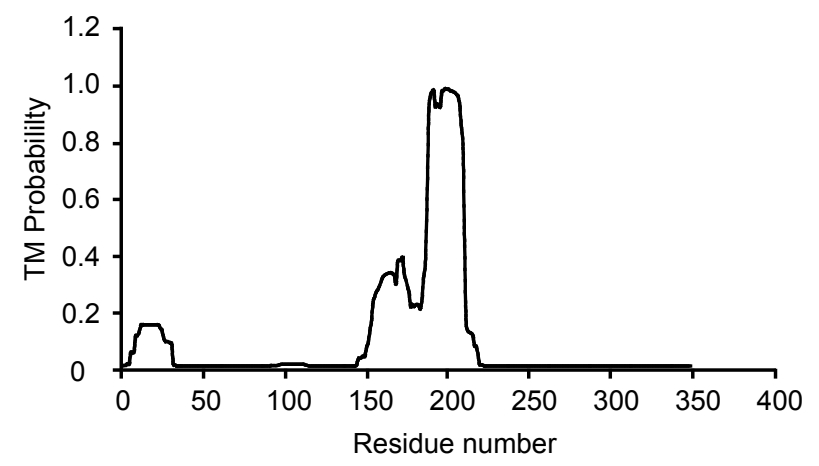

B

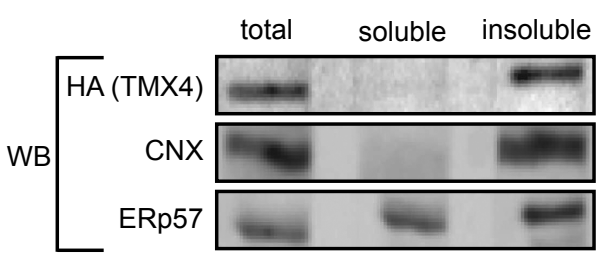

C
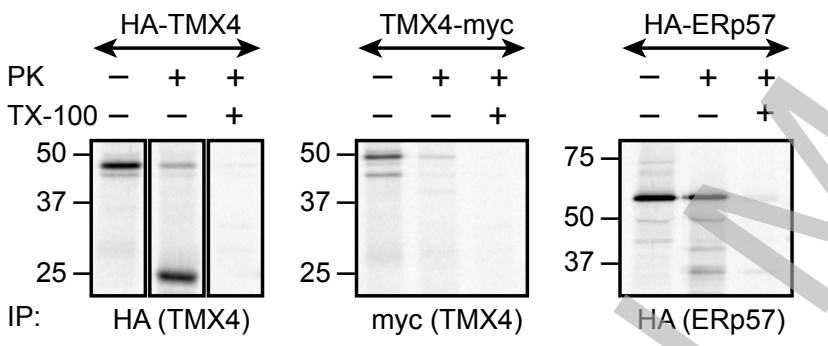

Roth et al. Figure 6 
Biochemical Journal Immediate Publication. Published on 08 Oct 2009 as manuscript BJ20091064

A

WT SP HA $=$ TrX

$\Delta$ tail SP HA $\quad$ TrX

KQK SP HA

CD4-tail SP HA $\quad$ TrX

B

IF: HA

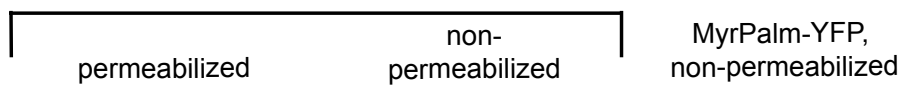

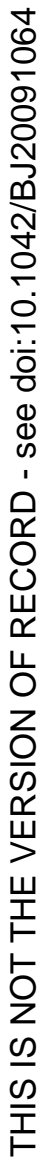

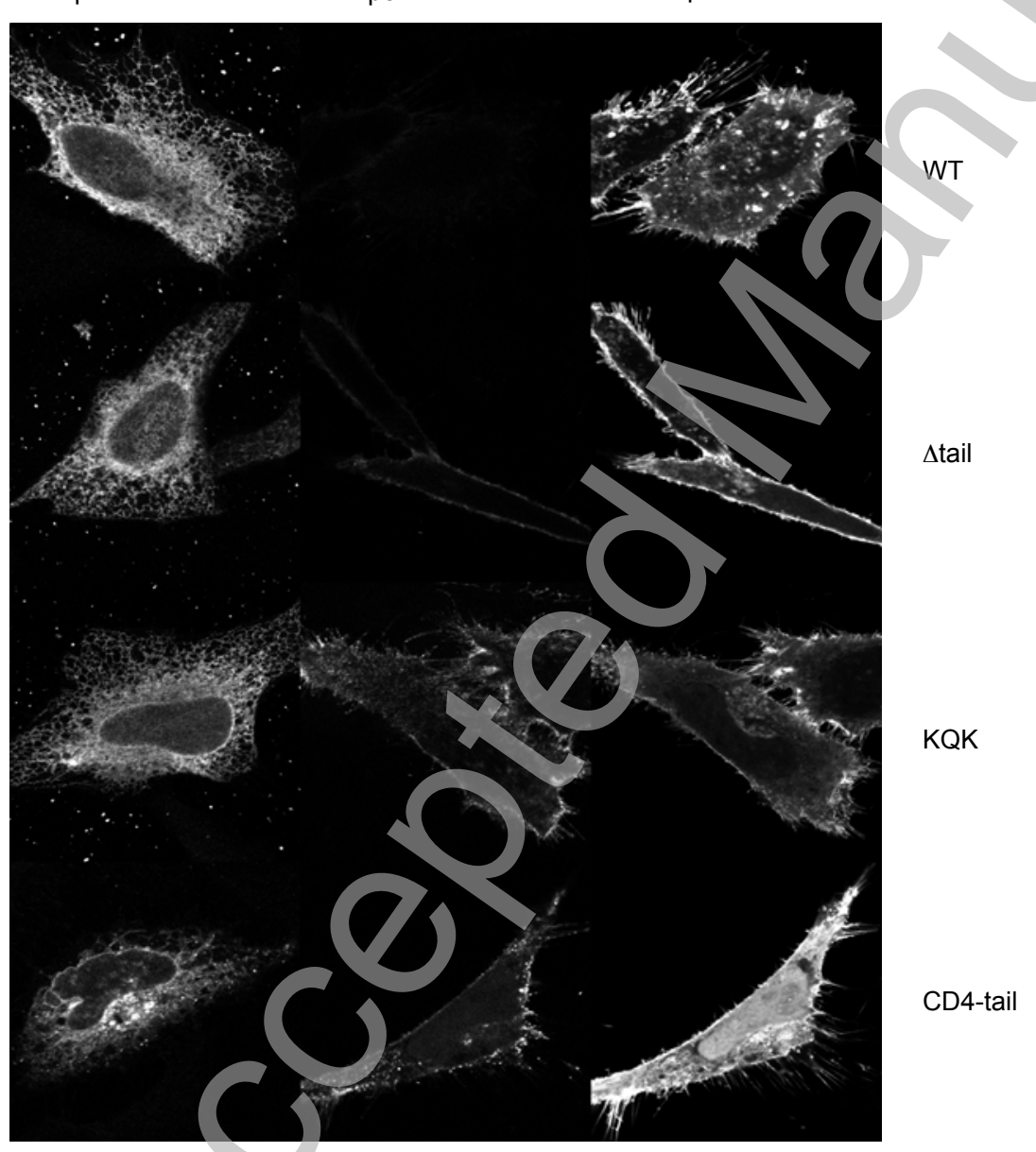

Roth et al. Figure 7 
Biochemical Journal Immediate Publication. Published on 08 Oct 2009 as manuscript BJ20091064

A

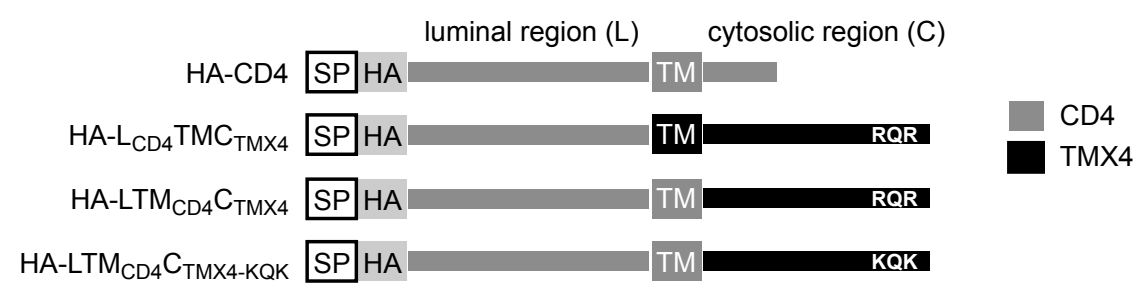

B

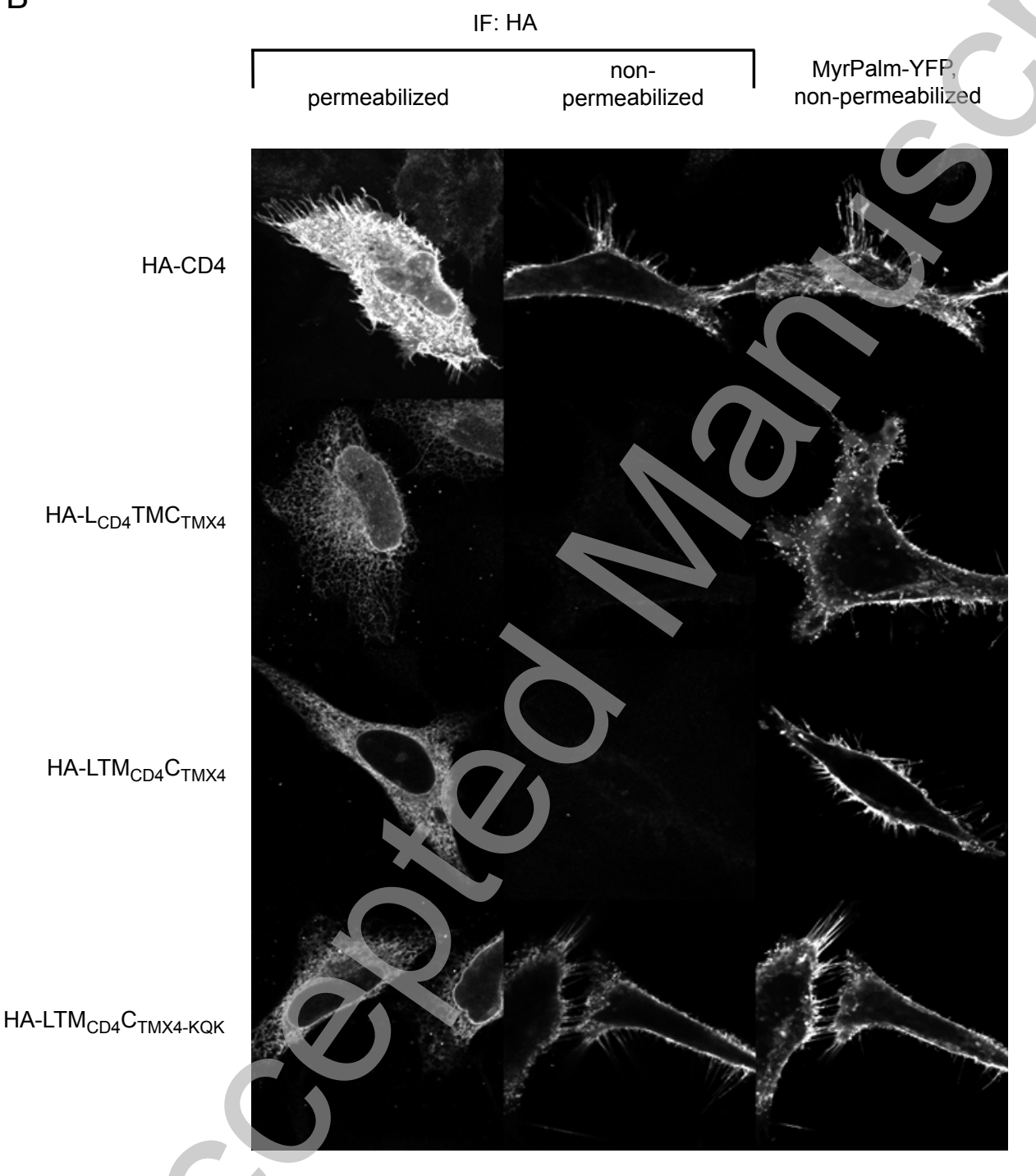

Roth et al. Figure 8

Licenced copy. Copying is not permitted, except with prior permission and as allowed by law. (C) 2009 The Authors Journal compilation (c) 2009 Portland Press Limited 